Marquette University

e-Publications@Marquette

$1-1-2008$

\title{
Isolation and X-ray Structural Characterization of Tetraisopropylpyrene Cation Radical
}

Moloy Banerjee

Marquette University

Vijay Vyas

Marquette University

Sergey V. Lindeman

Marquette University, sergey.lindeman@marquette.edu

Rajendra Rathore

Marquette University

Accepted version. Chemical Communications, No. 16 (2008): 1889-1891. DOI. (C) 2008 The Royal Society of Chemistry. Used with permission. 
Marquette University

e-Publications@Marquette

\section{Chemistry Faculty Research and Publications/College of Arts and Sciences}

This paper is NOT THE PUBLISHED VERSION; but the author's final, peer-reviewed manuscript. The published version may be accessed by following the link in the citation below.

Chemical Communications, No. 18 (2008): 1889-1891. DOI. This article is (C) The Royal Society of Chemistry and permission has been granted for this version to appear in e-Publications@Marquette. The Royal Society of Chemistry does not grant permission for this article to be further copied/distributed or hosted elsewhere without the express permission from The Royal Society of Chemistry.

\section{Isolation and X-ray Structural Characterization of Tetraisopropylpyrene Cation Radical}

Moloy Banerjee

Department of Chemistry, Marquette University, Milwaukee, WI

Vijay S. Vyas

Department of Chemistry, Marquette University, Milwaukee, WI

Sergey V. Lindeman

Department of Chemistry, Marquette University, Milwaukee, WI

Rajendra Rathore

Department of Chemistry, Marquette University, Milwaukee, WI

\section{Abstract}

A practical synthesis of 1,3,6,8-tetraisopropylpyrene and the isolation and X-ray structural characterization of its monomeric cation radical salt are described. 
Pyrene has been extensively utilized as a fluorescent probe for studying the conformational changes in proteins in solution owing to its long excited-state lifetime and characteristic excimer formation due to its self association. 1 The ability of pyrene to self associate into ordered structures has also been exploited in its usage as liquid crystalline materials. ${ }^{2}$ In stark contrast, it is this ability of $\pi-\pi$ stacking and excimer formation in solution and solid state that has limited the usage of pyrene as an emissive material in organic light-emitting diodes (OLED's) and related applications. ํ $^{2}$

Although, pyrene undergoes selective and quantitative bromination at the 1,3,6,8-positions to produce the corresponding tetrabromopyrene,, 4 attempted electrophilic substitutions to functionalize the pyrene core at the 1,3,6,8-positions with isopropyl groups, and thereby sterically congesting the flat fluorophore, 5 led to complex mixtures of polyalkylated pyrenes from which the separation of the desired isomer was rather tedious. 6

Our continuing interest in the design and syntheses of stable organic cation radicals or hole carriers, which are of fundamental importance to organic materials science,, led us to obtain an efficient and scalable route for the preparation of 1,3,6,8-tetraisopropylpyrene (3) and demonstrate the efficacy of sterically hindered tetraisopropylpyrene for the isolation and $\mathrm{X}$-ray crystallographic characterization of its monomeric cation-radical salt. The details of these findings are described herein.

After several failed attempts, in our hands, to synthesize 3 by Friedel-Crafts alkylation, 5 we resorted to a different approach as summarized in Scheme 1. Thus, a 4-fold Suzuki coupling between the readilyavailable 1,3,6,8-tetrabromopyrene, ${ }^{4}$ and isopropenylboronic acid, $\frac{8}{-}$ afforded cleanly the 1,3,6,8tetraisopropenylpyrene (2) in $>92 \%$ isolated yield. A catalytic hydrogenation of $\mathbf{2}$ over $10 \% \mathrm{Pd}-\mathrm{C}$ in a mixture of ethyl acetate-ethanol furnished 3 in quantitative yield. It was noted that under these hydrogenation conditions, the reduction of the pyrene core was not observed.
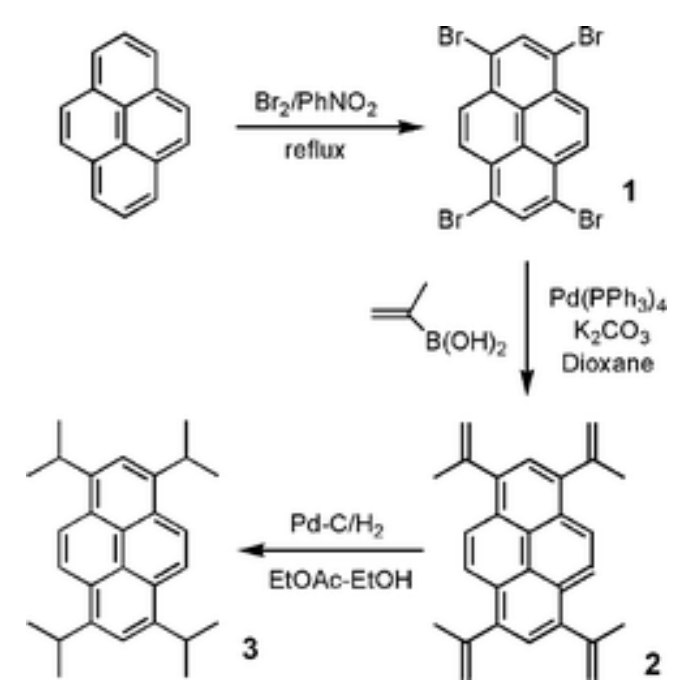

Scheme 1 Synthesis of 1,3,6,8-tetraisopropylpyrene (3).

The absorption spectrum of 3 in dichloromethane was characteristically similar to that of the parent pyrene with a modest bathochromic shift ( $\sim 30 \mathrm{~nm}$ ) owing to the alkyl substitutions. Furthermore, unlike the parent pyrene $=$ which showed a broad featureless excimer emission centered at $\sim 472 \mathrm{~nm}$ in the concentration range studied (0.05-0.1 M), the tetraisopropylpyrene 3showed only the monomeric emission (Fig. 1). As such, the observation of monomeric emission for 3 suggests that the bulky isopropyl groups exert sufficient steric 
inhibition to prevent a face to face approach of $\sim 3.5 \AA ̊$ necessary for an efficient $\pi$-stacking ${ }^{10}$ and consequent excimer formation (Fig. 1, right).
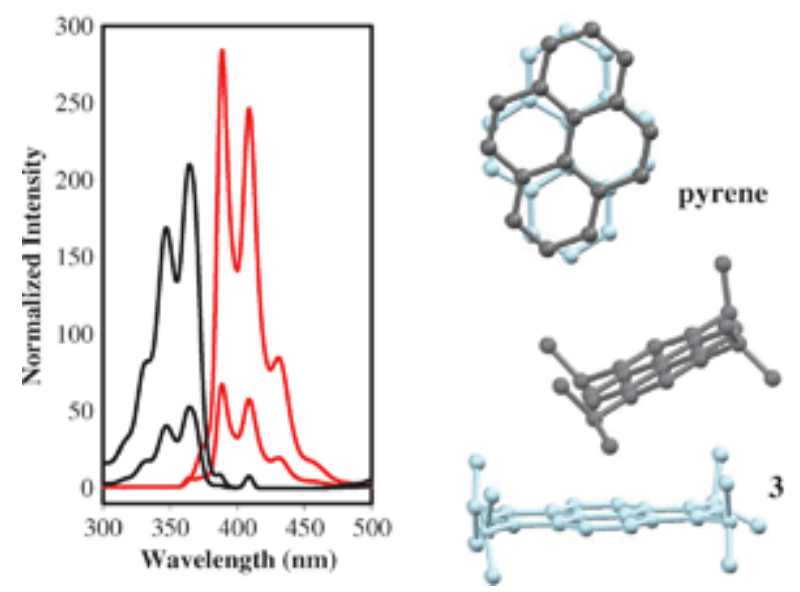

Fig. 1 Left: selected excitation (black lines) and emission (red lines) of 3 as dichloromethane solution ranging from a concentration of $1.66 \times 10^{-6} \mathrm{M}$ to $1.0 \times 10^{-5} \mathrm{M}$. Right: calculated structures of dimeric pyrene and 3 using DFT at B3LYP-631G* level.

Next with sufficient quantities of the tetraisopropylpyrene at our disposal, it was subjected to electrochemical oxidation at a platinum electrode as a $2 \times 10^{-3} \mathrm{M}$ solution in dichloromethane containing $0.2 \mathrm{Mn} n-\mathrm{Bu}_{4} \mathrm{NPF}_{6}$ as the supporting electrolyte. The cyclic voltammograms (Fig. 2, left) consistently met the reversibility criteria at various scan rates of $100-500 \mathrm{mV} \mathrm{s}^{-1}$, as they all showed cathodic/anodic peak current ratios of $i_{\mathrm{a}} / i_{\mathrm{c}}=1.0$ (theoretical) as well as the differences between anodic and cathodic peak potentials of $E_{\mathrm{pa}}-E_{\mathrm{pc}}=70 \mathrm{mV}$ at $22^{\circ} \mathrm{C}$. The reversible oxidation potential of $3\left(E_{\mathrm{ox}}=0.98 \mathrm{~V}\right.$ vs. SCE) was calibrated with added ferrocene as an internal standard $\left(E_{\mathrm{ox}}=\right.$ $0.45 \mathrm{~V}$ vs. SCE). It is important to note that under similar conditions as above, the parent pyrene undergoes an irreversible electrochemical oxidation at $E_{o x}=1.36 \mathrm{~V}$ vs. SCE.
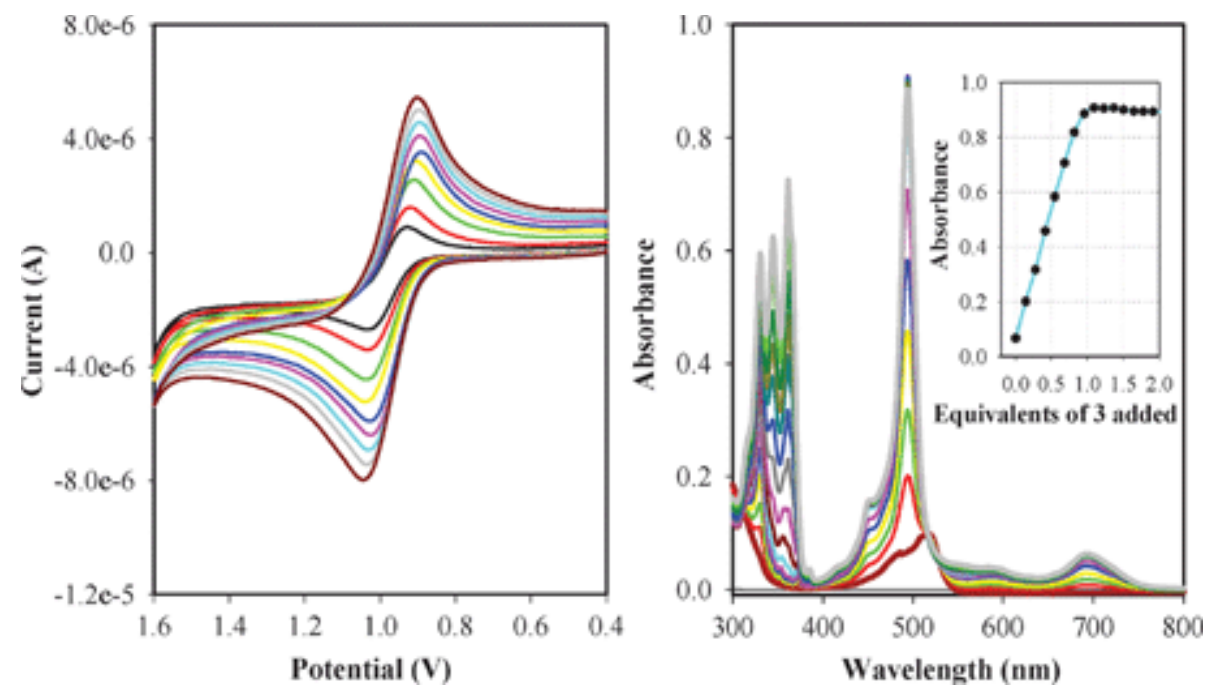

Fig. 2 Left: cyclic voltammograms of $2 \times 10^{-3} \mathrm{M} 3$ in $\mathrm{CH}_{2} \mathrm{Cl}_{2}$ containing $0.2 \mathrm{M} \mathrm{n}$-Bu $4 \mathrm{NPF}_{6}$ at scan rates between 100 and $500 \mathrm{mV} \mathrm{s}^{-1}$. Right: spectral changes upon the reduction of $1.33 \times 10^{-5} \mathrm{M} \mathrm{MA}^{-+}$by incremental addition 
of 3 in dichloromethane at $22^{\circ} \mathrm{C}$. Inset: a plot of increase in absorbance of $3^{\circ+}$ (monitored at $494 \mathrm{~nm}$ ) against the equivalent of added 3.

The electrochemical reversibility and relatively low oxidation potential of 3, prompted us to generate its cation radical by chemical oxidation using a stable aromatic cation radical salt ( $\mathrm{MA}^{-{ }^{+}} \mathrm{SbCl}_{6}{ }^{-} ; E_{\text {red }}=1.11 \mathrm{~V} v s$. SCE) as a one-electron oxidant. 11 Thus Fig. 2 (right) shows the spectral changes attendant upon an incremental addition of sub-stoichiometric amounts of tetraisopropylpyrene to a $1.3 \times 10^{-5} \mathrm{M} \mathrm{MA}^{++}\left[\lambda_{\max }(\log \varepsilon)=518 \mathrm{~nm}(3.86)\right]$ in dichloromethane at $22{ }^{\circ} \mathrm{C}$. Furthermore a plot of formation of the tetraisopropyl pyrene cation radical (i.e. increase in the absorbance at $494 \mathrm{~nm}$ ) against the increments of added neutral 3 (see inset of Fig. 2, right), established that $\mathrm{MA}^{-+}$was completely consumed after the addition of 1 equiv. of 3 ; and the resulting highly structured absorption spectrum of $3^{+}\left[\lambda_{\max }=330,345,362,494\right.$ ( $\left.\log \varepsilon=4.83\right), 451$ (sh), 590, and $\left.695 \mathrm{~nm}\right]$ remained unchanged upon further addition of neutral 3 (i.e.eqn (1)).

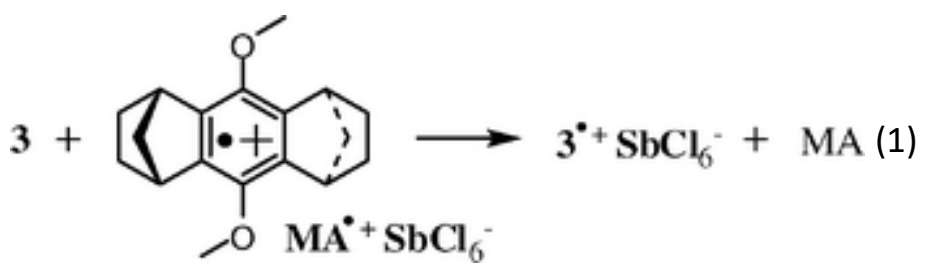

The green-colored solution of the $3^{\cdot+} \mathrm{SbCl}_{6}{ }^{-}$is highly persistent and did not show any decomposition at room temperature during the course of 12 hours. Moreover, a reduction of a dichloromethane solution of $3^{\cdot+}$ with zinc dust regenerated neutral 3 quantitatively, which further lends support to the high stability of the $3^{\cdot+}$. As in the neutral tetraisopropylpyrene which showed no signs of aggregation (i.e.Fig. 1), the formation of the dimeric cation radical resulting from the cofacial stacking of $3^{+}{ }^{+}$with neutral 3 , was not observed as judged by the singular absence of the charge-resonance transition in the NIR region in the presence of a large excess of 3 . Note that the parent pyrene cation radical readily forms a dimeric cation radical with characteristic absorption bands at 395 and $520 \mathrm{~nm}$ together with a broad charge-resonance transition centered at $\sim 1600 \mathrm{~nm} . \underline{\underline{12}}$

The high stability of the tetraisopropylpyrene cation radical in solution prompted us to isolate its crystalline salt by chemical oxidation using nitrosonium hexachloroantimonate as a 1-e- oxidant according to the stoichiometry in eqn (2).

$$
3+\mathrm{NO}^{+} \mathrm{SbCl}_{6}-\underset{0 \mathrm{C}}{\stackrel{\mathrm{DCM}}{\longrightarrow}} 3^{\bullet+} \mathrm{SbCl}_{6}^{-}+\mathrm{NO} \uparrow(2)
$$

Thus, a solution of 3 in anhydrous dichloromethane was added to crystalline $\mathrm{NO}^{+} \mathrm{SbCl}_{6}{ }^{-}$under an argon atmosphere at $\sim 0{ }^{\circ} \mathrm{C}$. The gaseous nitric oxide produced was entrained by bubbling argon through the solution to yield a green-colored solution, which upon spectrophotometric analysis indicated the formation of $3^{+} \mathrm{SbCl}_{6}{ }^{-}$(see Fig. 2). An excellent crop of dark-colored crystals, suitable for X-ray crystallographic studies, were obtained by a slow diffusion of toluene into the above solution of $3^{\circ}$ during a period of 2 days at $-20^{\circ} \mathrm{C}$.

The crystal structure of $3^{\cdot+} \mathrm{SbCl}_{6}{ }^{-}$revealed that cationic tetraisopropylpyrene moieties pack in a herringbone arrangement (see Fig. 3, left) with a pair of embedded toluene molecules. $¥$ One of the two crystallographically independent toluenemolecules forms an individual 1:1 complex with $3^{\circ+}$ while the other toluene molecule and the counteranion $\left(\mathrm{SbCl}_{6}^{-}\right.$) fill the space between the herringbone stacks of $3^{\cdot+}$ (see Fig. 3, left). $\S$ 


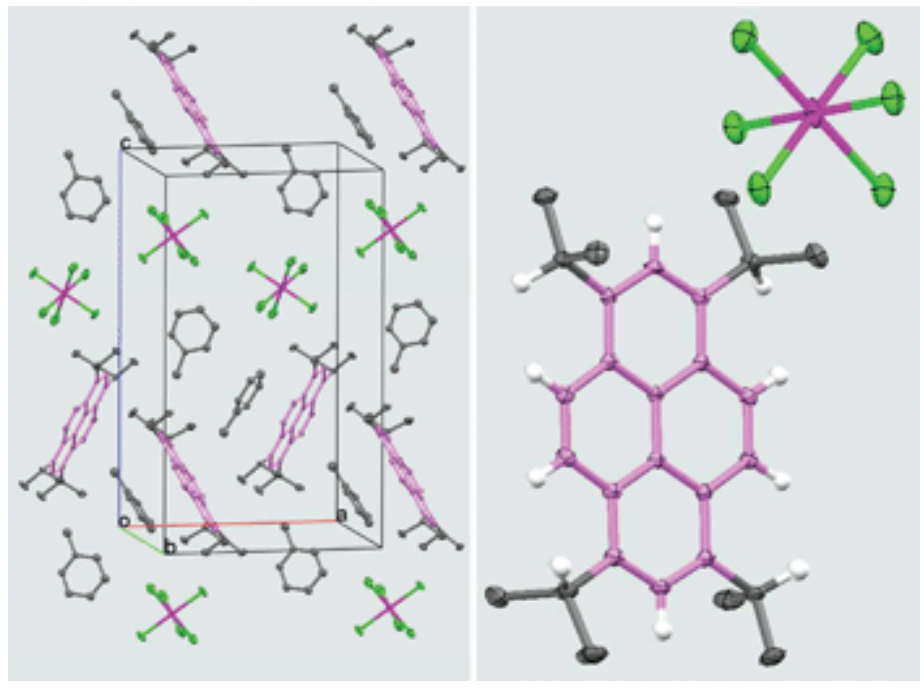

Fig. 3 The ORTEP diagram of $3^{+} \mathrm{SbCl}_{6}{ }^{-}$cation radical salt (right), with the packing diagram (left) showing that the toluenemolecules are embedded between the herringbone stacks of $3^{\cdot+}$. (The thermal ellipsoids are drawn with $55 \%$ probability.)

A closer look at the bond length changes in the cation radical $3^{\cdot+}$, together with a comparison with its neutral form, the structure of which was established by X-ray crystallography, points to the following important observations: (i) one electron oxidation causes no perceptible change in the bonds marked $\mathbf{A}\left(\mathrm{d}_{\mathrm{A}} 139 \mathrm{pm}\right)$ and $\mathbf{E}\left(\mathrm{d}_{\mathrm{B}} 142 \mathrm{pm}\right)$. (ii) The increased aromatization of the two internal rings of the pyrene molecule on oxidation occurs by a simultaneous lengthening of the short external bonds Band D by 2.2 and 2.9 pm, respectively, and shortening of the adjacent long bonds $\mathbf{C}$ by $2.1 \mathrm{pm}$. Interestingly, the bonds which undergo most dramatic lengthening in $3^{++}$(i.e. bonds $\mathbf{B}$ and $\mathbf{D}$ ) are the bonds on which the HOMO resides, i.e.Fig. 4 (right). (iii) The central bond $\mathbf{F}$ undergoes a shortening of $1.8 \mathrm{pm}$ in order to accommodate the changes in the bond lengths of various annulenic bonds (i.e.B, C, and D).
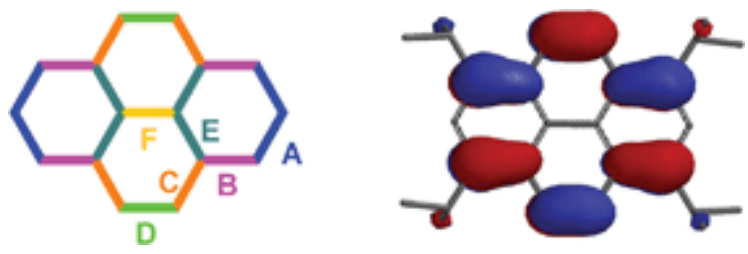

Fig. 4 Left: lettering scheme for the pyrene skeleton. Right: showing the localization of the HOMO of 3, obtained by DFT calculations at the B3LYP-631G** level, on bonds labelled B and D.

The experimental observations of the bond length changes upon 1-electron oxidation of 3 were found to be in reasonable agreement with the calculated values using DFT calculations at the B3LYP-631G** level (see Table 1).13 
Table 1 Experimental and theoretical bond lengths of the neutral and cation radical of 3 presented in picometres (pm)

\begin{tabular}{|c|c|c|c|c|c|c|}
\hline \multirow[b]{2}{*}{ Bond type 3} & \multicolumn{3}{|c|}{ B3LYP/6-31G** } & \multicolumn{3}{|c|}{ X-Ray data } \\
\hline & & $3^{\cdot+}$ & $\Delta$ & 3 & $3^{\cdot+}$ & $\Delta$ \\
\hline A & 139 & 6139.5 & $5-0.1$ & 138.9 (3) & $138.6(2)$ & -0.3 \\
\hline B & 141 & 7144.0 & +2.3 & 3141.1 (3) & $143.5(3)$ & +2.4 \\
\hline C & 143 & 5142.4 & 4 & 143.4 (3) & $141.2(3)$ & -2.2 \\
\hline D & 135 & 9138.0 & +2.1 & 134.7 (3) & 137.5 & +2.8 \\
\hline $\mathbf{E}$ & 143 & 4143.0 & $1-0.4$ & 142.7 (3) & 142.4 & -0.3 \\
\hline $\mathbf{F}$ & 144 & 0143.1 & -0.9 & 144.5 (3) & $142.7(4)$ & -1.8 \\
\hline
\end{tabular}

In summary, a simple and practical synthesis of 1,3,6,8-tetraisopropylpyrene (3) has been accomplished from readily available precursors. The emission and absorption spectroscopy of the neutral and cationic 3 clearly show that the $\pi$-stacking is inhibited owing to the presence of bulky isopropyl groups. The isolation and X-ray crystal structure determination of $3^{\cdot+} \mathrm{SbCl}_{6}{ }^{-}$as well as DFT calculations provide unequivocal evidence that introduction of a cationic charge (or polaron) in 3 largely affects the bonds on which the HOMO resides. Studies are underway for a more comprehensive investigation of the steric modulation of the $\pi$-stacking in various polyaromatic hydrocarbons.

\section{Notes and references}

(a) S. A. V. Arman and A. W. Czarnik, J. Am. Chem. Soc., 1990, 112, 5376 ; (b) M. Sassaroli, M. Ruonala, J. Virtanen, M. Vauhkonen and P. Somerharju, Biochemistry, 1995, 34, 8843 ; (c) A. Okamoto, K. Kanatani and I. Saito, J. Am. Chem. Soc., 2004, 126, 4820 ; (d) K. Fujimoto, H. Shimizu and M. Inouye, J. Org. Chem., 2004, 69, 3271 ; (e) I. V. Astakhova, A. D. Malakhov, I. A. Stepanova, A. V. Ustinov, S. L. Bondarev, A. S. Paramonov and V. A. Korshun, Bioconjugate Chem., 2007, 18, 1972 .

(a) S. A. Benning, T. Hassheider, S. Keuker-Baumann, H. Bock, F. D. Sala, T. Frauenheim and H.-S. Kitzerow, Liq. Cryst., 2001,28, 1105 ; (b) T. Hassheider, S. A. Benning, H.-S. Kitzerow, M.-F. Achard and H. Bock, Angew. Chem., Int. Ed., 2001, 40, 2060 ; (c) V. de Halleux, J.-P. Calbert, P. Brocorens, J. Cornil, J.-P. Declercq, J.-L. Bredas and Y. Geerts, Adv. Funct. Mater., 2004, 14, 649 ; (d) A. Hayer, V. D. Halleux, A. Koehler, A. ElGaroughy, E. W. Meijer, J. Barbera, J. Tant, J. Levin, M. Lehmann, J. Gierschner, J. Cornil and Y. H. Geerts, J. Phys. Chem. B, 2006, 110, 7653

(a) T. Oyamada, H. Uchiuzou, S. Akiyama, Y. Oku, N. Shimoji, K. Matsushige, H. Sasabe and C. Adachi, J. Appl. Phys., 2005, 98, 074506 ; (b) M. Muccini, Nat. Mater., 2006, 5, 605 ; (c) C.-H. Yang, T.-F. Guo and I.-W. Sun, J. Lumin., 2007, 124, 93 .

G. Venkataramana and S. Sankararaman, Eur. J. Org. Chem., 2005, 4162 .

M. Minabe, S. Takeshige, Y. Soeda, T. Kimura and M. Tsubota, Bull. Chem. Soc. Jpn., 1994, 67, 172 .

(a) I. L. Zvarich, A. P. Zaraiskii and O. I. Kachurin, Ukr. Khim. Zh. (Russ. Ed.), 1989, 55, 330 ; (b) A. Berg, J. Lam and P. E. Hansen, Acta Chem. Scand., Ser. B, 1986, B40, 665 ; (c) K. K. Laali, P. E. Hansen, E. Gelerinter and J. J. Houser, J. Org. Chem., 1993, 58, 4088 and references therein.

(a) M. Banerjee, S. V. Lindeman and R. Rathore, J. Am. Chem. Soc., 2007, 129, 8070 ; (b) J. K. Kochi, R. Rathore and P. L. Magueres, J. Org. Chem., 2000, 65, 6826 ; (c) R. Rathore, S. H. Abdelwahed and I. A. Guzei, J. Am. Chem. Soc., 2004, 126, 13582 ; (d) P. Debroy, R. Shukla, S. V. Lindeman and R. Rathore, J. Org. Chem., 2007, 72, 1765 and references therein.

G. A. Molander and M. Ribagorda, J. Am. Chem. Soc., 2003, 125, 11148 . 
(a) F. M. Winnik, Chem. Rev., 1993, 93, 587 ; (b) C. G. Echeverría, J. Am. Chem. Soc., 1994, 116, 6031.

R. Rathore, S. V. Lindeman and J. K. Kochi, J. Am. Chem. Soc., 1997, 119, 9393 and references therein.

R. Rathore, C. L. Burns, M. I. Deselnicu, S. E. Denmark and T. Bui, Org. Synth., 2005, 82, 1.

(a) A. Tsuchida, Y. Tsujii, M. Oboka and M. Yamamoto, J. Phys. Chem., 1991, 95, 5797 ; (b) Y. Mori, H. Shinoda, T. Nakano and T. Kitagawa, J. Phys. Chem. A, 2002, 106, 11743 ; (c) E. H. Ellison, J. Phys. Chem. B, 2004, 108, 4607 ; (d) M. Hara, S. Tojo, K. Kawai and T. Majima, Phys. Chem. Chem. Phys., 2004, 6, 3215.

Compare: (a) A. Pathak and S. Rastogi, Chem. Phys., 2006, 326, 315 ; (b) S. F. Nelsen, M. N. Weaver, D. Yamazaki, K. Komatsu, R. Rathore and T. Bally, J. Phys. Chem. A, 2007, 111, 1667.

Footnotes

† Electronic supplementary information (ESI) available: Synthetic details of 3 and procedure for the isolation of its cation radical. Crystallographic data for CCDC 674750 and 674751. See DOI: 10.1039/b800168e

¥ Crystal structure data for3. A suitable crystal $\left(0.20 \times 0.18 \times 0.06 \mathrm{~mm}^{3}\right)$ of 3 was obtained from a mixture of dichloromethaneacetonitrile solution at $22^{\circ} \mathrm{C}$. MW $=370.55$, triclinic, space group $P \overline{1}, a=11.3272(7), b=12.6764(7), c=16.9660(12) \AA, \alpha=$ $94.595(4)^{\circ}, b=92.311(4)^{\circ}, y=115.064(3)^{\circ}, D_{c}=1.123 \mathrm{Mg} \mathrm{m}^{-3}, V=2192.2(2) \AA^{3}, Z=4$. The total number of reflections measured were 25 845, of which 7547 reflections were symmetrically non-equivalent. Also note that unit cell contained one molecule in a general position and two half molecules lying about their inversion centres. Final residuals were $R 1=0.0644$ and $w R 2=0.1740$ for 7547 reflections with $/>2 \sigma(I)$. Crystal structure data for $\left[3^{+} \mathrm{SbCl}_{6}^{-}, 2 \mathrm{C}_{7} \mathrm{H}_{8}\right]$. A suitable crystal $\left(0.51 \times 0.23 \times 0.14 \mathrm{~mm}^{3}\right)$ of $3^{+} \mathrm{SbCl}_{6}{ }^{-}$was obtained from a mixture of dichloromethane-toluene solution at $-30^{\circ} \mathrm{C}$. MW $=889.27$, orthorhombic, space group Pnma, $a=13.8054(3), b=12.5572(3), c=23.6942(6) \AA ⿻, \alpha=90^{\circ}, b=90^{\circ}, \gamma=90^{\circ}, D_{c}=1.438 \mathrm{Mg} \mathrm{m}^{-3}, V=4107.56(17) \AA^{3}, Z=4$. The total number of reflections measured were 34504 , of which 3746 reflections were symmetrically non-equivalent. Final residuals were $R 1=0.0268$ and $w R 2=0.659$ for 3746 reflections with $I>2 \sigma(I)$. Note that all four components have crystallographically imposed mirror symmetry. CCDC numbers of complexes 3 and $\left[3^{+} \mathrm{SbCl}_{6}{ }^{-}, 2 \mathrm{C}_{7} \mathrm{H}_{8}\right]$ are 674750 and 674751.

$\S$ Note that a cofacial arrangement between the toluene and $3^{+}$at an inter-planar separation of $3.5 \AA$ may stabilize the cationic tetraisopropylpyrene via an electron-donor acceptor interaction. Also note that both the toluene molecules are rotationally disordered (within their respective molecular planes) with the occupations of the minor components being 23 and $37 \%$. 